MATHEMATICAL ASSOCIATION

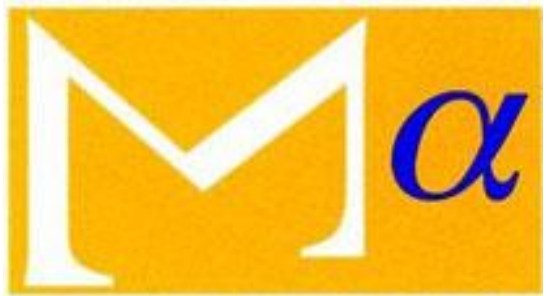

supporting mathematics in education

Approximations and Reductions

Author(s): A. Lodge

Source: The Mathematical Gazette, No. 3 (Dec., 1894), pp. 21-22

Published by: Mathematical Association

Stable URL: http://www.jstor.org/stable/3603996

Accessed: 31-12-2015 18:07 UTC

Your use of the JSTOR archive indicates your acceptance of the Terms \& Conditions of Use, available at http://www.jstor.org/page/ info/about/policies/terms.jsp

JSTOR is a not-for-profit service that helps scholars, researchers, and students discover, use, and build upon a wide range of content in a trusted digital archive. We use information technology and tools to increase productivity and facilitate new forms of scholarship. For more information about JSTOR, please contact support@jstor.org. 
By symmetry the remaining group of three follows.

The properties of the polar triangle form a corollary to the above equations.

G. HEPPEL.

4. Geometrical determination of $\mathrm{K}$ in the trilinear relation $a \beta=\mathrm{K} \gamma^{2}$.

$\mathrm{TQ}, \mathrm{TQ}^{\prime}$ (Fig. 11) are two tangents to a conic, $\mathrm{P}$ any point on the curve. Through $\mathrm{P}$ and the centre $\mathrm{O}$ are drawn lines $\mathrm{PG}, \mathrm{PH}, \mathrm{EPF}$, and $\mathrm{O} a, \mathrm{O} b, \mathrm{O} c$ parallel to $\mathrm{TQ}$, $\mathrm{TQ}^{\prime}, \mathrm{QQ}^{\prime}$ respectively. $\mathrm{PL}, \mathrm{PM}, \mathrm{PN}$ are perpendicular to $\mathrm{TQ}, \mathrm{TQ}^{\prime}, \mathrm{QQ}^{\prime}$.

Then, since the diameter $\mathrm{OT}$ bisects $\mathrm{QQ}^{\prime}, \mathrm{PP}^{\prime}$, and $\mathrm{EF}$, $\mathrm{EP}^{\prime}=\mathrm{PF}$.

$$
\begin{aligned}
\therefore \mathrm{O} c^{2}: \mathrm{O}^{2} & =\mathrm{EP} \cdot \mathrm{EP}^{\prime}: \mathrm{EQ}^{2}, \\
& =\mathrm{EP} \cdot \mathrm{PF}: \mathrm{EQ}^{2} .
\end{aligned}
$$

Since the right-angled triangles $\mathrm{PEL}, \mathrm{PGN}$ are similar,

$$
\therefore \mathrm{PE}: \mathrm{PG}(=\mathrm{EQ})=\mathrm{PL}: \mathrm{PN} \text {. }
$$

Similarly, $\quad \mathrm{PF}: \mathrm{PH}(=\mathrm{FQ})=\mathrm{PM}: \mathrm{PN}$,

$$
\therefore \mathrm{PE} . \mathrm{PF}: \mathrm{EQ} . \mathrm{FQ}^{\prime}=\mathrm{PL} . \mathrm{PM}: \mathrm{PN}^{2} \text {, }
$$

and

$$
\begin{aligned}
\mathrm{EQ}: \mathrm{FQ}^{\prime}=\mathrm{PG}: \mathrm{PH} & =\mathrm{TQ}: \mathrm{TQ}^{\prime}=\mathrm{O} a: \mathrm{O} b, \\
\therefore \frac{\mathrm{PL} \cdot \mathrm{PM}}{\mathrm{PN}^{2}}=\frac{\mathrm{PE} \cdot \mathrm{PF}}{\mathrm{EQ} \cdot \mathrm{FQ}^{\prime}} & =\frac{\mathrm{PE} \cdot \mathrm{PF}}{\mathrm{EQ}^{2}} \cdot \frac{\mathrm{EQ}}{\mathrm{FQ}^{\prime}}=\frac{\mathrm{O} c^{2}}{\mathrm{O} a^{2}} \cdot \frac{\mathrm{O} a}{\mathrm{O} b}, \\
& =\frac{\mathrm{O} c^{2}}{\mathrm{O} a \cdot \mathrm{O} b} .
\end{aligned}
$$

It can easily be deduced from the above that in the trilinear relation-

$$
\alpha \beta=\mathrm{K} \gamma \delta,
$$

if $\mathrm{O} a, \mathrm{O} b, \mathrm{O} c, \mathrm{O} d$ are the semi-diameters parallel to the four lines to which $\alpha, \beta, \gamma, \delta$ are respectively perpendicular,

$$
\mathrm{K}=\frac{\mathrm{O} c . \mathrm{O} d}{\mathrm{O} a . \mathrm{O} b} \quad \text { J. J. MiLNe. }
$$

5. On the centroid of a trapezoid.

Let ABCD (Fig. 12) be a trapezoid whose parallel sides $\mathrm{AB}, \mathrm{DC}$ contain $p$ and $q$ units of length respectively. Bisect $\mathrm{AB}, \mathrm{DC}$ at $\mathrm{E}, \mathrm{F}$, and let $\mathrm{BD}, \mathrm{EF}$ cut at $\mathrm{H}$.

By VI. 1 triangle $\mathrm{ABD}$ : triangle $\mathrm{BDC}:: \mathrm{AB}: \mathrm{DC}$,

$$
\begin{aligned}
& :: p: q, \\
& :: 3 p: 3 q .
\end{aligned}
$$

The centroid of triangle $\mathrm{ABD}$ is that of masses $2 p$ at $\mathrm{E}$ and $p$ at $\mathrm{D}$. The centroid of triangle $\mathrm{BDC}$ is that of masses $2 q$ at $\mathrm{F}$ and $q$ at $\mathrm{B}$.

Now

$$
\begin{aligned}
\mathrm{EH}: \mathrm{HF} & :: \mathrm{BH}: \mathrm{HD}, \\
& :: \mathrm{BE}: \mathrm{DF}, \\
& :: p: q .
\end{aligned}
$$

Hence masses $p$ at $\mathrm{D}$ and $q$ at $\mathbf{B}$ are equivalent to a mass $p+q$ at $\mathrm{H}$, and therefore to masses $p$ at $\mathbf{F}$ and $q$ at $\mathbf{E}$.

Hence the system has the centroid of masses $2 p+q$ at $\mathrm{E}$ and $p+2 q$ at $\mathbf{F}$.

$\therefore$ it is at $\mathrm{G}$ on $\mathrm{EF}$ where $(2 p+q) \mathrm{EG}=(p+2 q) \mathrm{FG}$.

If we denote the centroids of triangles $\mathrm{ABD}, \mathrm{BDC}$ by $\mathrm{L}$ and M, and adopt the notation of Möbius, the latter part of the demonstration would run thus-

$$
\begin{aligned}
(3 p+3 q) \mathrm{G} & =3 p \mathrm{~L}+3 q \mathbf{M}, \\
& =2 p \mathbf{E}+p \mathbf{D}+2 q \mathbf{F}+q \mathbf{B}, \\
& =2 p \mathbf{E}+2 q \mathbf{F}+(p+q) \mathbf{H}, \\
& =2 p \mathbf{E}+2 q \mathbf{F}+q \mathbf{E}+p \mathbf{F}, \\
& =(2 p+q) \mathbf{E}+(2 q+p) \mathbf{F} .
\end{aligned}
$$

E. M. LANGLEY.

\section{On a proof of XI. 4 .}

Euclid's own demonstration, being rather long, is now usually superseded either by the demonstration which Legendre gives in his Elements of Geometry, Bk. V. prop. 4, or by a third demonstration in which the perpendicular is produced to the other side of the plane. In Wilson's Solid Geometry this third method of proof is ascribed (erroneously) to Legendre, and in my own edition of Euclid to A. L. Crelle. The latter certainly gives it, without any hint of its authorship, in an article (dated 1834) in his Journal, vol. xlv. pp. 35, 36 (1853). He had however published it, along with the proofs of Euclid and Legendre, in his Lehrbuch der Elemente der Geometrie, vol. ii. p. 532 (1827), and added the remark: "This proof is by Cauchy."

The correctness of this ascription to Cauchy is confirmed by Lacroix, who gives the proof in his Elements of Geometry, $\S 196$ (12th edition, 1822), with the note:

"This demonstration, of the same kind as that of Euclid but simpler, has been communicated to me by Mr. Cauchy, a very distinguished young geometer." J. S. MACKAY.

\section{APPROXIMATIONS AND REDUCTIONS.}

(Continued from No. 1, which contains fully-worked numerical examples of the application of the methods of "Practice" to such multipliers as those given below.)

"It is an abiding delusion of the opponent of decimals that he will suppose the decimalist to be under a contract never to use a common fraction."-De Morgan.

7. Degrees to radians $\quad 01745329$ $\frac{1}{60}\left(1+\frac{1}{20}\right)\left(1-\frac{1}{400}-\frac{1}{6000}\right)=\cdot 01745333$.

8. Minutes to radians .000290888

(i) $\cdot 00029\left(1+\frac{3}{1000}\right) \quad=\cdot 00029087$,

(ii) $\cdot 0006\left(\frac{1}{2}-\frac{1}{70}-\frac{1}{1100}\right)=\cdot 000290883$.

9. Seconds to radians .00000484814 $\cdot 00001\left(\frac{1}{2}-\frac{1}{70}-\frac{1}{1100}\right) \quad=\cdot 00000484805$.

10. Revolutions p. min. to radians p. sec. $\cdot 104719755$ $\frac{1}{10}\left(1+\frac{1}{20}\right)\left(1-\frac{1}{400}-\frac{1}{6000}\right)=\cdot 10472$.

11. Radians p. sec. to revolutions p. min. $9 \cdot 5493$ $10\left(1-\frac{3}{100}-\frac{3}{200}\right)=10\left(1-\frac{1}{20}+\frac{1}{200}\right)=9 \cdot 55$, i.e. multiply by 10 and subtract $4 \frac{1}{2}$ per cent.

12. Miles to kilometres $1 \cdot 60933$ $2\left(1-\frac{1}{5}\right)\left(1+\frac{1}{200}+\frac{1}{1400}\right)=1 \cdot 609 \frac{3}{7}$,

or $\frac{10}{6}\left(1-\frac{1}{30}-\frac{1}{1000}\right) \quad=1.609 \frac{4}{9}$.

13. Kilometres to miles $\quad 62138$

(i) $\left(\frac{1}{2}+\frac{1}{8}\right)\left(1-\frac{1}{2} \frac{1}{00}-\frac{1}{140 \sigma}\right)=\cdot 6214 \frac{2}{7}$,

(ii) $\cdot 6+\frac{1}{70}+\frac{1}{140} \quad=\cdot 6214 \frac{2}{7}$.

Note that, approximately, 5 miles $=8$ kilometres, or a mile and a quarter (i.e. 10 furlongs) $=2$ kilometres, so that if our mile were increased by a quarter of its present length, the series miles, furlongs, chains, and links would 
from a decimal system of measures just double the corresponding measures of the metric system.

At a rate of $3 \frac{3}{4}$ miles per hour, a kilometre is a 10 minutes' walk, so that 6 kilometres an hour is a little easier than our 4 miles-an-hour standard of good walking.

14. Common to Napierian logarithms

(i) $2 \cdot 3+\frac{1}{400}\left(1+\frac{1}{30}\right)$

(ii) $2 \cdot 3+\frac{1}{400}\left(1+\frac{1 \cdot 02}{30}\right)$

$2 \cdot 302585$

$=2 \cdot 31) 258 \frac{1}{3}$,

$=2 \cdot 302585$.

15. Napierian to common logarithms

43429448

(i) $\frac{1}{3}+\frac{1}{10}+\frac{1}{100 \overline{0}}-\frac{1}{30000}$

$=\cdot 4343$,

(ii) $4343\left(1-\frac{1}{80} \frac{1}{000}\right)$

$=\cdot 43429457$,

(iii) $\frac{1}{3}+\frac{1}{10}+\frac{1}{1000}-\frac{1}{30000}\left(1+\frac{1}{6}\right)=4342944 \frac{4}{9}$,

(iv) $\frac{1}{3}+\frac{1}{9}-\cdot 01015$

$=\cdot 4342944 \frac{4}{9}$.

EXAMPLE. - Find $\log _{\mathrm{e}} 5$ by (14 ii), and reconvert to common $\operatorname{logs}_{\mathrm{s}}$ by (15 ii) and (15 iv), being given that $\log _{10} 5$ $=\cdot 6989700$.

\begin{tabular}{rrr}
.6989700 & 1.6094370 & 1.6094370 \\
\cline { 2 - 3 } 1.3979400 & .5364790 & $-\frac{.5364790}{2096910}$ \\
174742 & 1609437 & 17882633 \\
5825 & 160944 & .71530533 \\
29 & .69903214 & 1609437 \\
\cline { 2 - 3 } 1.6094370 & 5365 & 16094 \\
& 894 & 8047 \\
& .69896955 & .69896955
\end{tabular}

Note. - The identity $\left(3+\frac{1}{7}\right)(1-\cdot 0004)=3 \cdot 1416$ given in No. 1 had been previously noted and applied to numerical computation by Professor Genese in Milne's Companion to Problem Papers, p. 252.

\section{SOLUTIONS OF EXAMINATION QUESTIONS.}

The Editor will be glad to avail himself of the help of all classes of readers towards making this section of the Gazette as useful as possible. Mathematical Tutors are invited to send neat solutions; STUDENTs to call attention to classes of problems presenting exceptional difficulties, and ExAMINERs who sympathise with us to forward copies of their papers. The help of foreign readers is especially requested in obtaining copies of papers set in the public examinations of other countries.

The Editor acknowledges with thanks the receipt of the following sets of papers :-

University of Edinburgh (Junior, Senior, and Advanced Honours).

Harvard University, 1893-94.

King's College, London, June 1894.

Vassar College, New York, June 1894.

Cambridge Higher Locals, June 1894.

West Point, Jan. 1894.

12. (i) Find for real values of $x$ the least and greatest values of $x+\sqrt{6 x-7-x^{2}}$. (ii) Find by algebra the greatest value of

$$
\begin{gathered}
x \sqrt{3}+\sqrt{1-x^{2}} . \\
x+\sqrt{6 x-7-x^{2}} \ldots(a) \\
=x-3+\sqrt{2-(x-3)^{2}}+3 .
\end{gathered}
$$

Now $\left\{x-3+\sqrt{2-(x-3)^{2}}\right\}^{2}+\left\{x-3-\sqrt{2-(x-3)^{2}}\right\}^{2}$ $=4$.

Hence $\left\{x-3+\sqrt{2-(x-3)^{2}}\right\}$ is numerically greatest when $x-3-\sqrt{2-(x-3)^{2}}=0$.

Hence its least and greatest values are -2 and +2 .

Hence the least and greatest values of the given expression $(a)$ are 1 and 5 respectively. (See Milne's Companion to Problem Papers, p. 9.)

The above example may be easily illustrated by a graph.

Putting $\quad y=x+\sqrt{6 x-7-x^{2}} \ldots(b)$ we obtain $\quad(x-3)^{2}+(y-x)^{?}=2$.

From which it is clear the graph is an ellipse (Fig. 13) which has $x-3=0, y-x=0$ for conjugate diameters, its equation referred to those diameters being $\mathrm{X}^{2} / 4+\mathrm{Y}^{2} / 2=1$.

The points at which the tangents to the graph are parallel to the axis of $x$ are, from simple geometrical reasons, those for which $\mathrm{X} / \sqrt{2}=\mathrm{Y}= \pm 1$, i.e. at which

$$
\begin{aligned}
& x=3 \pm \mathrm{X} \sqrt{2}=4 \text { or } 2, \\
& y=x+\mathrm{Y}=5 \text { or } 1 .
\end{aligned}
$$

It is worthy of remark that the graphic method enables us to deal readily with the restricted case in which the radical in $(a)$ is to be taken with the positive sign only, the minimum value of $y$ being now $3-\sqrt{2}$.

For an investigation of graphic methods see Chrystal's Algebra, ch. xv.

The "turning values" of $(a)$ might also be found by considering the equation $(b)$ as a quadratic in $x$. If $x$ is to be real we find that $(y-5)(y-1)$ is not to be positive.

They may also be found by putting-

$$
\text { whence } \quad \begin{aligned}
x-3 & =r \cos , \phi \sqrt{6 x-7-x^{2}}=r \sin \phi, \\
y & =\sqrt{2}(\sin \phi+\cos \phi)+3, \\
& =2 \sin \left(\phi+\frac{\pi}{4}\right)+3 .
\end{aligned}
$$

Here, if we are restricted to the positive sign of the radical, we have only to deal with the range of values from $\phi=0$ to $\phi=180$.

hence

$$
\begin{gathered}
\text { Put } x \sqrt{3}=m, \sqrt{1-x^{2}}=n \\
m^{2}+3 n^{2}=3 .
\end{gathered}
$$

Now

$$
\begin{aligned}
(m-3 n)^{2}+3(m+n)^{2} & =4 m^{2}+12 n^{2} \\
& =12,
\end{aligned}
$$

hence $m+n$ is greatest when $m=3 n$, which gives $m+n=2$.

We have here a particular case of the identity

$$
(p m-q n)^{2}+p q(m+n)^{2}=(p+q)\left(p m^{2}+q n^{2}\right),
$$

whence $p$ and $q$, being positive constants,

(a) $m+n$ is greatest for a given value of $p m^{2}+q n^{2}$,

(B) $p m^{2}+q n^{2}$ is least for a given value of $m+n$ if $p m=q n$.

13. $\mathrm{PQ}$ is a focal chord and $\mathrm{R}$ any point on the conic. If $\mathrm{PR}, \mathrm{QR}$ meet the directrix in $\mathrm{T}$ and $\mathrm{U}$, show that $\mathrm{XT}$. XU is constant. 